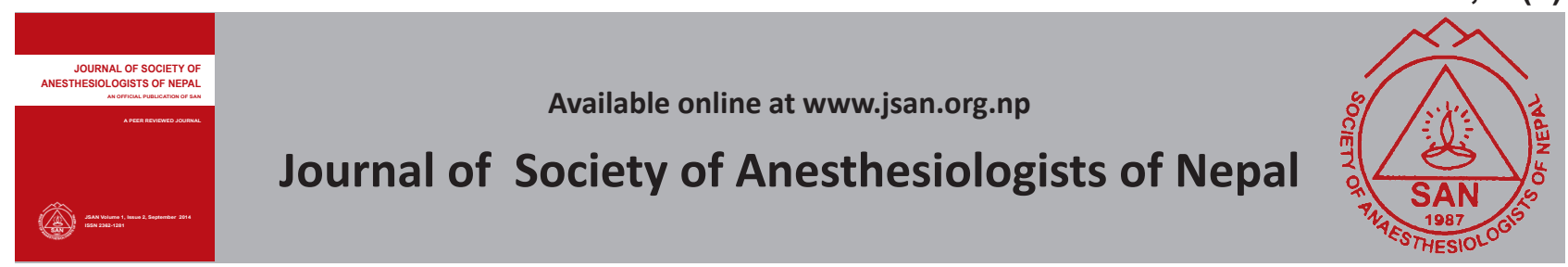

Case Report

\title{
Anaesthetic management for laparoscopic cholecystectomy in a child
} Kumar Nishant*, Balkrishna Bhattarai*, Shailesh Adhikary ${ }^{* *}$

*Department of Anaesthesiology and Critical Care, BP Koirala Institute of Health Sciences, Dharan, Sunsari, Nepal.

${ }^{* *}$ Department of Surgery, BP Koirala Institute of Health Sciences, Dharan, Sunsari, Nepal.

A R T I C L E I N F O
Article history
Received 08.08 .2014
Accepted 28.08 .2014
Published 08.09 .2014
C Authors retain copyright
and grant the journal right
of first publication with the
work simultaneously licensed
under a Creative Commons
Attribution License that allows
others to share the work with
an acknowledgement of the
work's authorship and initial
publication in this journal.

\begin{abstract}
Laparoscopic surgical techniques offer several advantages over conventional open surgery. However, anaesthesia for laparoscopic surgical procedures is challenging due to various associated physiological consequences mainly of intra-peritoneal carbon dioxide insufflation and positioning. Gall stone disease is rare in pediatric age group and therefore, experience of anaesthetic management in such a condition is limited. Here we describe anaesthetic management of a 56-month-old male child scheduled for laparoscopic cholecystectomy for gall stone disease.
\end{abstract}

Key words: Anaesthesia, Laparoscopic cholecystectomy, Paediatric surgery

How to cite this article: Nishant K, Bhattarai B, Adhikary S. Anaesthetic management for laparoscopic cholecystectomy in a child. JSAN 2014;1:83-85.

\section{Introduction}

Although paediatric laparoscopy was first described as early as 1923 by Kelling, its regular and widespread use has increased relatively recently. A laparoscopic approach offers several advantages over open surgical procedures including reduction of surgical stress and fluid shifts, less need for postoperative analgesia, reduction of postoperative respiratory and wound complications, less need of intensive care unit admission and stay, rapid return to normal diet and decreased overall hospital stay. ${ }^{1}$ At the same time laparoscopic procedures pose certain

challenges more remarkably in paediatric patients. The anaesthetic management in these cases poses special problems due to pneumoperitoneum created and extremes of position adopted in addition to the fact that paediatric anaesthesia itself is a challenge. ${ }^{2}$ Gallstones in children are uncommon and most are due to some underlying disorder like spherocytosis, thalassemia and sickle cell disease. Gall stone in small children in absence of such disorders is rare. With the rarity of gall stone disease in children experience in anaesthetic management

Correspondence: Balkrishna Bhattarai

Department of Anaesthesiology and Critical Care,

BP Koirala Institute of Health Sciences, Dharan, Sunsari, Nepal.

Telephone: +97725525555 Ext-2006

Fax: +97725520251

Email: bhattaraibk@yahoo.com, 
of laparoscopic cholecystectomy is very limited. Therefore the purpose of this case report is to share our experience of anaesthetic management of laparoscopic cholecystectomy in a 56-month-old child.

\section{Case Report}

A 56-month-old male child from Mirgauliya Village Development Committee, Ward Number-8, Sunsari District of Nepal was incidentally found to have gall stone disease at the age of one year. The child was brought to the surgical Out Patient Department (OPD) of our hospital with complaints of gradual onset of pain in upper abdomen on right side for the preceding one month. Pain was mild in intensity, non-radiating and dull aching in character. There was no obvious aggravating or relieving factor. There was no history of vomiting, haematemesis, fever, jaundice, per rectal bleed, malaena, altered coloured stool, burning micturition and haematuria. He had history of an episode of febrile seizures during infancy but was not on any medication at present.

The child weighed $14 \mathrm{~kg}$. Findings of general and systemic examinations were unremarkable. Complete blood count, blood chemistries and peripheral smear were all within normal limits. Abdominal ultrasound revealed a solitary internal echogenic area of $14.7 \mathrm{~mm}$ at neck region of gallbladder causing distal acoustic shadow.

The child was premedicated with syrup promethazine hydrochloride $5 \mathrm{mg}$ on the night before and on morning of surgery. After shifting the child to operating table, monitor was attached and baseline NIBP, heart rate and $\mathrm{SpO}_{2}$ were recorded. Anaesthesia was induced with halothane in oxygen followed by securing of intravenous access with $22 \mathrm{G}$ intravenous cannula on dorsum of right hand. Inj. atropine $0.2 \mathrm{mg}$, fentanyl $25 \mu \mathrm{g}$ and vecuronium 1.5 mg was given intravenously immediately after securing IV access. Trachea was intubated with $5.0 \mathrm{~mm}$ internal diameter (ID) cuffed endotracheal (ET) tube after manually ventilating for three minutes. The tube was fixed at $15 \mathrm{~cm}$ marking at the angle of mouth.

Patient was kept under mechanical ventilation with initial settings of respiratory frequency-16, tidal volume (VT)-180 mL and inspiration: expiration (I:E) ratio-1:2. Anaesthesia was maintained with isoflurane in oxygen and ventilation was adjusted to maintain eucapnia. Surgery was performed using standard 4 port technique using two $10 \mathrm{~mm}$ trocar and two $5 \mathrm{~mm}$ trocar. Intraoperative vitals remained within normal limits and patient's trachea was extubated following reversal of neuromuscular blockade with intravenous neostigmine $0.75 \mathrm{mg}$ and glycopyrrolate $0.15 \mathrm{mg}$. Mean airway pressure remained in the range of 5-7 $\mathrm{mmHg}$ and intra-abdominal pressure (IAP) was kept below $10 \mathrm{mmHg}$. Six millilitre of $0.25 \%$ bupivacaine was instilled on gall bladder bed and another $6 \mathrm{~mL}$ of $0.25 \%$ bupivacaine was infiltrated around trocar insertion site for providing post-op analgesia. Inj ondansetron $2 \mathrm{mg}$ was given intravenously as prophylaxis for postoperative nausea vomiting (PONV). Total duration of anaesthesia was 70 minutes. Intraoperative period remained unremarkable.

\section{Discussion}

Although laparoscopic approach to paediatric abdominal surgeries has become common and routine, experience in laparoscopic cholecystectomy in small children is limited due to rarity of gall stone disease in small children. Moreover, specific laparoscopic surgical procedures have specific physiologic consequences and anaesthetic challenges and it is true for laparoscopic cholecystectomy also.

During laparoscopic procedures, the pneumoperitoneum and increase in IAP induces cephalad shift of diaphragm. This reduces functional residual capacity (FRC) and total thoracic compliance and increase in airway ressistance. ${ }^{3}$ Increase in IAP involves changes in myocardial contractility and systemic vascular resistance (SVR). A decreased venous return and increased SVR decreases cardiac output (CO). After IAP rises to $12 \mathrm{mmHg}$, there is an increase in SVR and afterload, leading to fall in preload and $\mathrm{CO}^{4}$

Understandably, a more careful approach is required in infants and children. Restriction of IAP to $6 \mathrm{mmHg}$ in infants and to $12 \mathrm{mmHg}$ in older children has been recommended. These pressures have been found to have minimal effects on cardiac index. ${ }^{2}$ Sakka et $\mathrm{al}^{5}$ found that the cardiac index decreased significantly when IAP was increased to $12 \mathrm{mmHg}$. Huettemann et al. found significant septal hypokinesia at an IAP of $12 \mathrm{mmHg}$ in paediatric patients undergoing laparoscopic surgery. ${ }^{6}$ In our patient the IAP was kept below $10 \mathrm{mmHg}$ and all the time we did not observe any episode of hypotension or bradycardia throughout the conduct of anaesthesia.

Other occasional problems occurring during laparoscopy include endobronchial intubation, subcutaneous emphysema, pnuemothorax, pneumomediastinum, massive $\mathrm{CO}_{2}$ embolism, bronchospasm, bronchial hypersecretion and atelectasis. ${ }^{7}$ Reports of such complications in children are expectedly limited. We did not observe any such complications in our patient.

An increase in the mean peak inspiratory pressure during volume controlled ventilation to $16.2 \mathrm{cmH}_{2} \mathrm{O}$ from a baseline value of $13.6 \mathrm{cmH}_{2} \mathrm{O}$ in the head down position and to $17.9 \mathrm{cmH}_{2} \mathrm{O}$ during insufflation of $\mathrm{CO}_{2}$ has been reported in a French retrospective study. ${ }^{3}$ In our patient peak airway pressure and mean inspiratory pressure were low in the range of $10-12 \mathrm{mmHg}$ and $5-7 \mathrm{mmHg}$ respectively throughout the period of mechanical ventilation. This is most likely due to limited intra-abdominal pressure and that our patient was rather head up as required for laparoscopic cholecystectomy.

End tidal $\mathrm{CO}_{2}\left(\mathrm{EtCO}_{2}\right)$ concentration has been shown to increase and exceed $50 \mathrm{mmHg}$ in $15 \%$ of cases in small children undergoing brief laparoscopic procedure under general anaesthesia. ${ }^{3}$ Mild degrees of permissive 
hypercarbia has been shown to be generally well tolerated by the vast majority of patients without posing significant clinical threat. ${ }^{8}$ In our patient, the $\mathrm{EtCO}_{2}$ concentration reached up to $55 \mathrm{mmHg}$ but rapidly returned to baseline after stopping $\mathrm{CO}_{2}$ insufflation and adjustment of ventilation. Studies have shown that it takes $10 \mathrm{~min}$ to normalize $\mathrm{EtCO}_{2}$ after completion of laparoscopy. ${ }^{9}$

\section{Conclusion}

It is possible that with vigilant observation and tailored management approach, anaesthetic management for laparoscopic cholecystectomy in small children can be safely accomplished even in a set up used for adults.

\section{References}

1. Pretorius M, Rasmussen GE, Holcomb GW. Hemodynamic and catecholamine responses to a laparoscopic adrenalectomy for pheochromocytoma in a pediatric patient. Anesth Analg 1998;87:1268-70.

2. Gupta R, Singh R. Challenges in paediatric laparoscopic surgeries. Indian J Anaesth 2009;53:560-6.

3. Wedgewood J, Doyle E. Anaesthesia and laproscopic surgery in children. Paediatr Anaesth 2001;11:391-9.

4. Mary K. Laparoscopic abdominal procedures in children, anaesthetic implications. The Indian Anaesthesists Forum. January 2009. www. theiaforum.org/anaesthesia-articles-archive.html accessed on 29.07.2014.

5. Sakka SG, Huettemann E, Petrat G, Meier-Hellman A, Schier F, Reinhart K. Transoesophageal echocardiographic assessment of haemodynamic changes during laparoscopic herniorrhaphy in small children. Br J Anaesth 2000;84:330-4.

6. Huettemann E, Sakka SG, Petrat G, Schier F, Reinhart K. Left ventricular regional wall motion abnormalities during pneumoperitoneum in children. Br J Anaesth 2003;90:733-6.

7. Jean JL. Anaesthesia for laparoscopic surgery. In: Roy CF, Edward Miller D, Gerald RJ, Michael RF, John SF, editors. Anaesthesia. 5th Edition. California: Churchill Livingstone; 2000. pp. 2140-54.

8. Bannister CF. Anesthesia considerations for laparoscopic procedures in children. www.pedsanesthesia.org/meetings/2006 accessed on 29.07.2014.

9. Rowney DA, Aldridge IM. Laparoscopic fundoplication in children: anaesthetic experience of 51 cases. Paediatr Anaesth 2000;10:A2916. 